\title{
Food Pantry Making a Difference for FHSU Students
}

Chase Willhite

Associate VP for Communication at the Kansas Health Foundation.

\begin{abstract}
Across Kansas, as students like Shane Keller face increasing economic challenges, food insecurity becomes an issue. But, with the help of a Kansas Health Foundation Healthy Living Grant, students at Fort Hays State University now have access to fresh fruits and vegetables through the Tiger Food Exchange. We would like to acknowledge the work and support on this project by Scenic Road Productions out of Roeland Park, KS. To learn more about this innovative program, please view the Health Happenings video.
\end{abstract}

\section{http://kansashealth.org/success-stories/hh-august2017/}

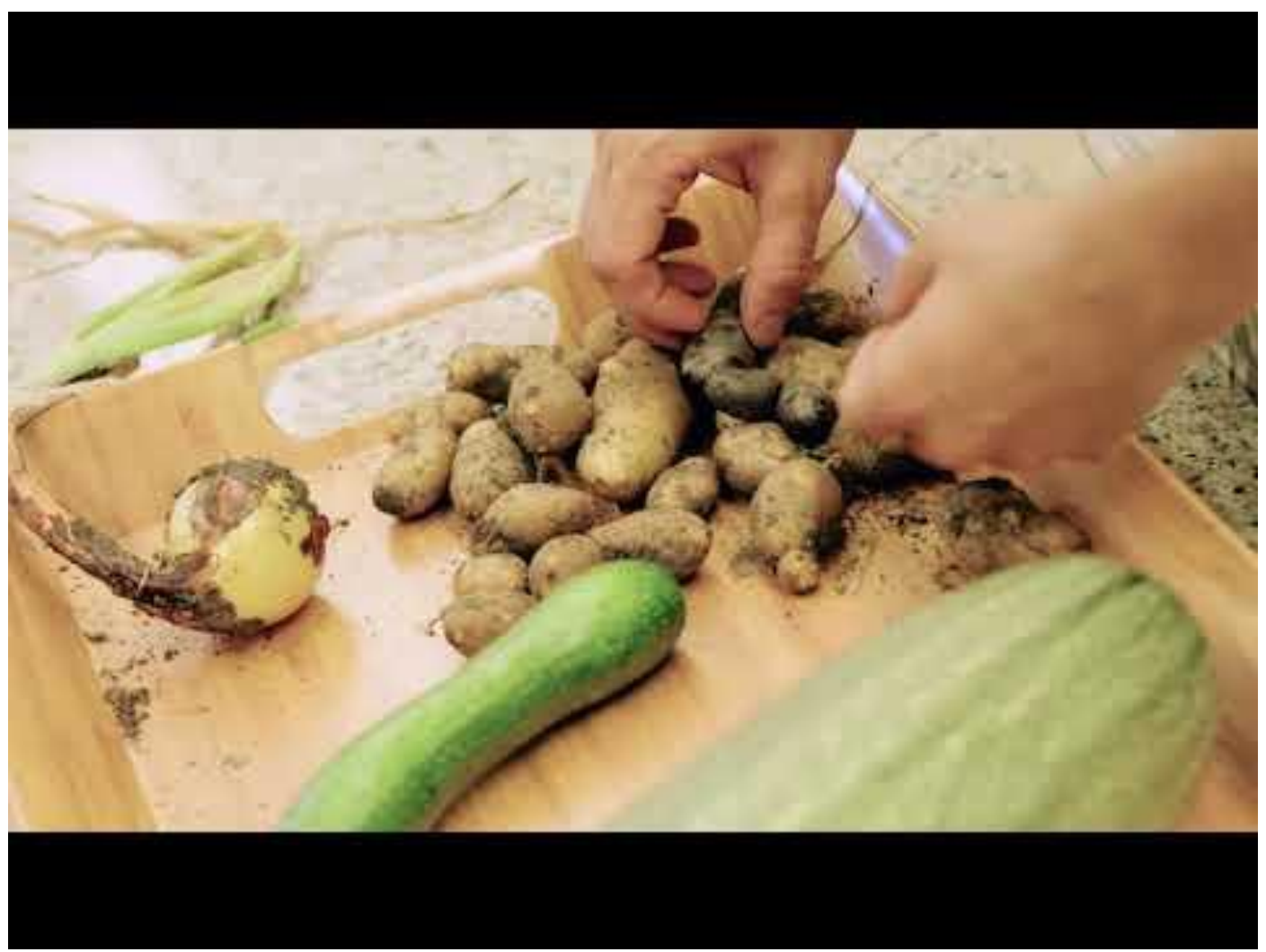




\section{Author Biography}

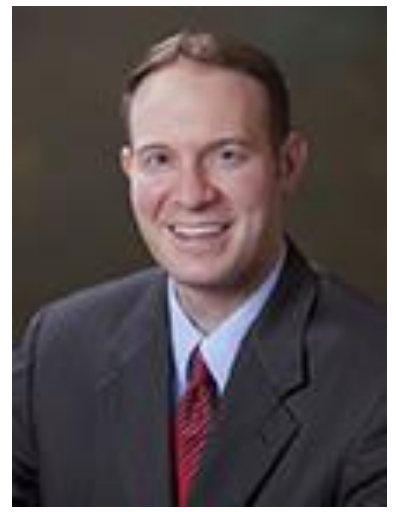

Chase Willhite joined the Kansas Health Foundation in 2006, and today serves as the Associate Vice President for Communication. During his years at KHF, Willhite has managed all aspects of the organization's internal and external communication initiatives, including digital media, public awareness campaigns and publications. He is a graduate of Wichita State University, where he earned a BA in Journalism, and from Baker University where he earned an MBA.

\section{Chase Willhite}

Associate Vice President for Communication

cwillhite@khf.org

309 E. Douglas

Wichita, KS 67202

Tel 316-491-8455

Tel 800-373-7681

Fax 316-262-2044 